\section{Case Reports in Nephrology and Dialysis}

Case Rep Nephrol Dial 2020;10:95-103

DOI: $10.1159 / 000508785$

Published online: September 11, 2020

(C) 2020 The Author(s)

Published by S. Karger AG, Basel www.karger.com/cnd

This article is licensed under the Creative Commons Attribution-NonCommercial 4.0 International License (CC BY-NC) (http://www.karger.com/Services/OpenAccessLicense). Usage and distribution for commercial purposes requires written permission.

\title{
Multiple Myeloma-Associated Light Chain Amyloidosis and a Proposed Approach to Monoclonal Immunoglobulin-Associated Renal Disease
}

\author{
Zi Yun Chang ${ }^{\mathrm{a}}$ Thomas Paulraj Thamboo $^{\mathrm{b}}$ Clarice Shi Hui Choong ${ }^{\mathrm{c}}$ \\ Weng Kin Wong ${ }^{a} \quad$ Clara Lee Ying Ngoha \\ aDepartment of Medicine, National University Health System, Singapore, Singapore; \\ ${ }^{b}$ Department of Pathology, National University Heath System, Singapore, Singapore; \\ 'Department of Haematology-Oncology, National University Cancer Institute, National \\ University Health System, Singapore, Singapore
}

\section{Keywords}

Immunoglobulin deposition disease $\cdot$ Myeloma $\cdot$ Amyloidosis

\begin{abstract}
Many challenges remain in diagnosing monoclonal immunoglobulin-associated renal disease, despite widespread application of immunofluorescence (IF) and immunohistochemistry. Here, we report a newly diagnosed case of multiple myeloma with clinical suspicion of renal amyloidosis, which had negative IF staining for kappa and lambda light chains in the glomeruli. Although laser microdissection and mass spectrometry-based proteomic analysis have emerged as important tools for amyloid typing in the literature, such facilities are still not widely available in Asia. We propose that a clinicopathological algorithm for the evaluation of organized
\end{abstract}




\section{Case Reports in Nephrology and Dialysis}

Case Rep Nephrol Dial 2020;10:95-103

DOI: $10.1159 / 000508785$

(c) 2020 The Author(s). Published by S. Karger AG, Basel www.karger.com/cnd

Chang et al.: Multiple Myeloma-Associated Light Chain Amyloidosis and a Proposed Approach to Monoclonal Immunoglobulin-Associated Renal Disease

monoclonal renal deposits, together with a combined nephrological-haematological approach, will still be adequate to generate an unequivocal diagnosis in the majority of cases.

(C) 2020 The Author(s)

Published by S. Karger AG, Basel

\section{Introduction}

Light chain (AL) amyloidosis is the most frequently diagnosed entity amongst monoclonal immunoglobulin (MIg)-associated renal diseases. Making a distinction between varying MIgassociated nephropathies can be challenging due to nonspecific staining on immunofluorescence (IF) and immunohistochemistry (IHC). This is likely related to the varied physicochemical and protein conformational properties of pathogenic MIgs. We present a case of multiple myeloma with AL amyloidosis, where glomerular deposits did not demonstrate sufficient light chain restriction, and a proposed clinicopathological algorithm to aid diagnosis.

\section{Case Description}

A 54-year-old Asian male presented with facial and lower limb oedema. There was no significant medical history (including diabetes mellitus and hypertension) or family history of renal disease. Physical examination revealed a blood pressure of 100/45 mm Hg. He had anasarca with no palpable lymph nodes or hepatosplenomegaly.

Laboratory evaluation demonstrated abnormal serum creatinine of $270 \mu \mathrm{mol} / \mathrm{L}$ with nephrotic syndrome (urine protein to creatinine ratio $19 \mathrm{~g} / \mathrm{g}$, serum albumin $21 \mathrm{~g} / \mathrm{dL}$ ), haematocrit level of $22 \%$ and serum kappa to lambda free light chain ratio of 0.03 . Serum M-protein was undetected. Subsequent serologic workup, including autoimmune serologies, infectious workup and anti-neutrophil cytoplasmic antibody (ANCA) studies were negative. Serum Creactive protein and serum amyloid $A(S A A)$ were not elevated at $<5 \mathrm{mg} / \mathrm{dL}$ (range 10-45 $\mathrm{mg} / \mathrm{dL}$ ) and $4 \mathrm{mg} / \mathrm{L}$ (range $0-322 \mathrm{mg} / \mathrm{L}$ ), respectively. Laboratory results are summarised in Table 1. Baseline renal function was unknown.

A native renal biopsy was performed to evaluate the nephrotic syndrome with presumed acute kidney injury. On light microscopy, there were deposits of an amorphous substance in the mesangium and some capillary loops of the glomeruli (Fig. 1a), as well as in the interstitium, arteries and arterioles. Three of 19 glomeruli contained cellular crescents (Fig. 1b). The deposits stained weakly with periodic acid-Schiff stain and were pale on haematoxylin and eosin stain. There was also a focal "cock's comb" appearance in the glomeruli on periodic-acid silver stain. Amyloid was confirmed by the deposits exhibiting diffuse congophilia with applegreen birefringence seen under polarized light. In the glomeruli, however, this birefringence was weak and focal (Fig. 2a). While the deposits within the interstitium and arterioles demonstrated lambda light chain restriction by IF, the deposits in the glomeruli were negative for IgG, IgA, IgM, C1 q, C3, fibrin and kappa and lambda light chains. Repeated IF on formalin-fixed and paraffin-embedded tissue after proteinase digestion yielded similar results. On immunohistochemical staining, the deposits in the glomeruli, blood vessels and interstitium were positive for amyloid $\mathrm{P}$ but were negative for amyloid A. The deposits were also positive for 


\section{Case Reports in Nephrology and Dialysis}

Case Rep Nephrol Dial 2020;10:95-103

DOI: $10.1159 / 000508785$

(c) 2020 The Author(s). Published by S. Karger AG, Basel www.karger.com/cnd

Chang et al.: Multiple Myeloma-Associated Light Chain Amyloidosis and a Proposed Approach to Monoclonal Immunoglobulin-Associated Renal Disease

thioflavin T. There was no vasculitis or atypical tubular casts. Mild interstitial fibrosis and tubular atrophy were present (approximately 15\%).

Haematology was consulted urgently to evaluate for a lymphoproliferative disorder. Bone marrow biopsy showed 10-15\% lambda-light chain-restricted plasma cells, diagnostic of multiple myeloma. No amyloid protein was found in the bone marrow. Separately, radiographs showed a lytic lesion in the right humerus. Cardiac ultrasonographic examination revealed a thickened myocardium wall suspicious for cardiac amyloid.

Renal electron microscopy results returned from the pathologist 4 days later, confirming the presence of electron dense deposits within the mesangium, some glomerular capillary loops and the tubular basement membrane. These deposits were composed of randomly oriented fibrils with a diameter of approximately $8 \mathrm{~nm}$ (Fig. 2b). In many areas, the mesangial deposits appeared partially washed out. No unstructured deposits or tubuloreticular inclusions were identified.

The final diagnosis was multiple myeloma-associated AL amyloidosis, with glomerular crescents. He was planned for high-dose chemotherapy with cyclophosphamide, bortezomib and dexamethasone followed by autologous stem cell transplant. However, chemotherapy was complicated in its 4th month by respiratory failure from Pneumocystis jirovecii pneumonia requiring ventilatory support. Subsequent months of chemotherapy were interrupted by recurrent admissions for mucositis leading to dehydration and malnutrition. His renal function continued to decline, and he was initiated on dialysis 5 months after his initial diagnosis.

\section{Discussion}

This case illustrates the fact that despite widespread availability of IF and IHC, many challenges remain in diagnosing MIg-associated renal diseases. This is compounded by the fact that pathogenic MIgs are known to have varied physicochemical properties, giving rise to a wide spectrum of renal lesions or multiple renal manifestations in a single patient $[1,2]$. In this case, the glomerular deposits did not show lambda light chain restriction congruent with the diagnosis of AL amyloidosis, although there was congophilia with focal weak birefringence under polarised light.

Several possibilities need to be considered for this interesting phenomenon. The first is if another type of amyloid process was involved. However, the clinical suspicion for hereditary amyloidosis was low, given that the patient had neither family history of renal disease nor extra-renal manifestations of peripheral dysautonomia or liver impairment, common in amyloid transthyretin amyloidosis [3]. Other hereditary amyloid nephropathies, such as hereditary fibrinogen amyloidosis, have a distinct histological appearance of marked glomerular amyloid deposition with obliterated capillary lumens and minimal extraglomerular deposition features not apparent in this patient $[3,4]$. Furthermore, the patient's initial clinical management would be unchanged regardless, as he required cyclical chemotherapy for treatment of multiple myeloma and AL amyloidosis.

The alternative possibility of a concomitant glomerular pathology, such as fibrillary glomerulonephritis (FGN), has to be considered, given the presence of renal crescents, which is otherwise rare in AL amyloidosis [5]. Most reported cases of crescentic glomerulonephritis and concurrent amyloidosis have been seen with type AA amyloidosis due to serum amyloid 


\section{Case Reports in Nephrology and Dialysis}

Case Rep Nephrol Dial 2020;10:95-103

DOI: $10.1159 / 000508785$

(c) 2020 The Author(s). Published by S. Karger AG, Basel www.karger.com/cnd

Chang et al.: Multiple Myeloma-Associated Light Chain Amyloidosis and a Proposed Approach to Monoclonal Immunoglobulin-Associated Renal Disease

A protein, in the clinical setting of rheumatoid arthritis or malignancy. In this patient, extensive autoimmune serologies did not point to a second glomerular disease. DnaJ homolog subfamily B member 9 (DNAJB9) IHC has been developed as a highly specific marker for FGN but is not available in local laboratories [6]. However, Nasr et al. [6] demonstrated in a recent study that paraffin IF unmasked polytypic IgG deposits in 43\% of FGN initially believed to have light chain restriction on routine IF. The study authors hence concluded that DNAJB9-positive FGN was not associated with monoclonal gammopathy in the vast majority (>98\%) of patients. This casts new questions on whether FGN can even be considered a differential in MIgassociated renal disease [7].

Instead, the phenomenon of weakly staining glomeruli deposits could have been due to circulating plasma proteins which became non-specifically trapped by amyloid precursors in the glomeruli, masking relevant stains [8]. Alternatively, the quantities of circulating MIg may have been too minute.

Nonetheless, we acknowledge that the absence of certain techniques for protein typing in our laboratory are limitations for definitive exclusion of a different amyloid process. Current IHC techniques using commercial antibody-based amyloid typing have limited ability to detect the full spectrum of amyloid precursor proteins [8]. Laser microdissection (LMD) combined with mass spectrometry (MS)-based proteomics has recently emerged as a valuable tool for identifying protein signatures associated with different amyloid nephropathies [8-10]. LMD/MS would be additionally useful in this patient to exclude FGN, given the electron dense deposits seen on electron microscopy [8, 9]. In addition, spectrometry overcomes the problem of inadequate tissue for repeated IF, as it can be performed on a paraffin block without additional reagents. LMD/MS has also been reported in the literature to be useful in cases of membranoproliferative glomerulonephritis associated with MIg where deposits were masked and undetected by IF [11].

However, the usage of LMD/MS will remain limited across Asia because it requires the aid of a highly experienced laboratory and is associated with significant setup costs $[10,12]$. Our institution did not have a renal LMD/MS facility. Local pathology units are disincentivized because MIg-associated renal disease remains a rare entity, despite systemic monoclonal gammopathies affecting an estimated $4 \%$ of the general population. While efforts need to be made to acquire such highly specialised tools in a centralised unit, we recognise that the majority of institutions here in Asia will not have direct access to LMD/MS and, thus, propose a clinicopathological algorithmic approach to renal diseases with MIg deposits (Fig. 3).

We believe that in the majority of cases, careful evaluation and correlation of light microscopy, IF and ultrastructural findings, properly integrated with the clinical history and laboratory data, generally would provide enough information to generate an unequivocal diagnosis. This is true of our case. Based on this algorithmic approach, a nephrological-haematological approach becomes necessary for prognostication and treatment purposes once a MIg-related renal disease is suspected $[2,13]$. There should be a low threshold for both native kidney and bone marrow biopsies, respectively, even if biopsy of one organ has isolated a preliminary diagnosis [2,14]. Said et al. [3] have proposed that there are specific cases where LMD/MS may still remain necessary (Table 2). These include equivocal Congo red stain where clinical evaluation was unable to rule out a FGN, and all cases with positive IF staining for immunoglobulin heavy chains, where routine IF/IHC often is unable to type the amyloid deposits. 


\section{Case Reports in Nephrology and Dialysis}

Case Rep Nephrol Dial 2020;10:95-103

\section{Conclusion}

Despite widespread application of IF and IHC, many challenges remain in diagnosing MIgassociated renal disease. This is partially due to the wide and heterogenous spectrum and properties of monoclonal precursor proteins. Occasionally, histological findings do not fit into a classical picture. When advanced ancillary techniques like LMD/MS are not widely available, such as in Asia, careful evaluation of clinicopathological evidence and a combined nephrological-haematological approach, where appropriate, may still help to generate an unequivocal diagnosis.

\section{Statement of Ethics}

The patient gave written informed consent for this case to be published (including images). The research was conducted ethically in accordance with the World Medical Association Declaration of Helsinki.

\section{Conflict of Interest Statement}

The manuscript has not been published previously in whole or part. The authors have no conflicts of interest to declare.

\section{Funding Sources}

No funding was obtained for this project.

\section{Author Contributions}

Z.Y.C. and C.L.Y.N. contributed to patient care and writing the manuscript. Histopathology images and description were provided by T.P.T. All authors reviewed and approved the final version of the manuscript.

\section{References}

1 Bridoux F, Leung N, Hutchison CA, Touchard G, Sethi S, Fermand JP, et al.; International Kidney and Monoclonal Gammopathy Research Group. Diagnosis of monoclonal gammopathy of renal significance. Kidney Int. 2015 Apr;87(4):698-711.

2 Kim JH, Kim JW, Kim YN, Kim HI, Kim JY, Kwon GY, et al. Progression of monoclonal gammopathy with undetermined significance to multiple myeloma diagnosed by kidney biopsy: A case report. Case Rep Nephrol Dial. 2015 Sep;5(3):180-6.

3 Said SM, Sethi S, Valeri AM, Leung N, Cornell LD, Fidler ME, et al. Renal amyloidosis: origin and clinicopathologic correlations of 474 recent cases. Clin J Am Soc Nephrol. 2013 Sep;8(9):1515-23. 


\section{Case Reports in Nephrology and Dialysis}

Case Rep Nephrol Dial 2020;10:95-103

DOI: $10.1159 / 000508785$

(C) 2020 The Author(s). Published by S. Karger AG, Basel www.karger.com/cnd

Chang et al.: Multiple Myeloma-Associated Light Chain Amyloidosis and a Proposed Approach to Monoclonal Immunoglobulin-Associated Renal Disease

4 Gillmore JD, Lachmann HJ, Rowczenio D, Gilbertson JA, Zeng CH, Liu ZH, et al. Diagnosis, pathogenesis, treatment, and prognosis of hereditary fibrinogen A $\alpha$-chain amyloidosis. J Am Soc Nephrol. 2009 Feb;20(2):444-51.

5 Yamagata H, Satoskar A, Kim J, Marein S, Maroz N. Crescentic glomerulonephritis related to AL amyloidosis. Am J Kidney Dis. 2018;71(4):598.

6 Nasr SH, Vrana JA, Dasari S, Bridoux F, Fidler ME, Kaaki S, et al. DNAJB9 is a specific immunohistochemical marker for fibrillary glomerulonephritis. Kidney Int Rep. 2017 Aug;3(1):56-64.

7 Said SM, Leung N, Alexander MP, Cornell LD, Fidler ME, Grande JP, et al. DNAJB9-positive monotypic fibrillary glomerulonephritis is not associated with monoclonal gammopathy in the vast majority of patients. Kidney Int. 2020;98(2):498-504.

8 Sethi S, Rajkumar SV, D'Agati VD. The complexity and heterogeneity of monoclonal immunoglobulinassociated renal diseases. J Am Soc Nephrol. 2018 Jul;29(7):1810-23.

9 Leung N, Bridoux F, Batuman V, Chaidos A, Cockwell P, D'Agati VD, et al. The evaluation of monoclonal gammopathy of renal significance: a consensus report of the International Kidney and Monoclonal Gammopathy Research Group. Nat Rev Nephrol. 2019 Jan;15(1):45-59.

10 Sethi S, Vrana JA, Theis JD, Leung N, Sethi A, Nasr SH, et al. Laser microdissection and mass spectrometrybased proteomics aids the diagnosis and typing of renal amyloidosis. Kidney Int. 2012 Jul;82(2):226-34.

11 Larsen CP, Messias NC, Walker PD, Fidler ME, Cornell LD, Hernandez LH, et al. Membranoproliferative glomerulonephritis with masked monotypic immunoglobulin deposits. Kidney Int. 2015 Oct;88(4):867-73.

12 Vrana JA, Gamez JD, Madden BJ, Theis JD, Bergen HR 3rd, Dogan A. Classification of amyloidosis by laser microdissection and mass spectrometry-based proteomic analysis in clinical biopsy specimens. Blood. 2009 Dec;114(24):4957-9.

13 Khalighi MA, Dean Wallace W, Palma-Diaz MF. Amyloid nephropathy. Clin Kidney J. 2014 Apr;7(2):97-106.

14 Haubitz M, Peest D. Myeloma-new approaches to combined nephrological-haematological management. Nephrol Dial Transplant. 2006 Mar;21(3):582-90.
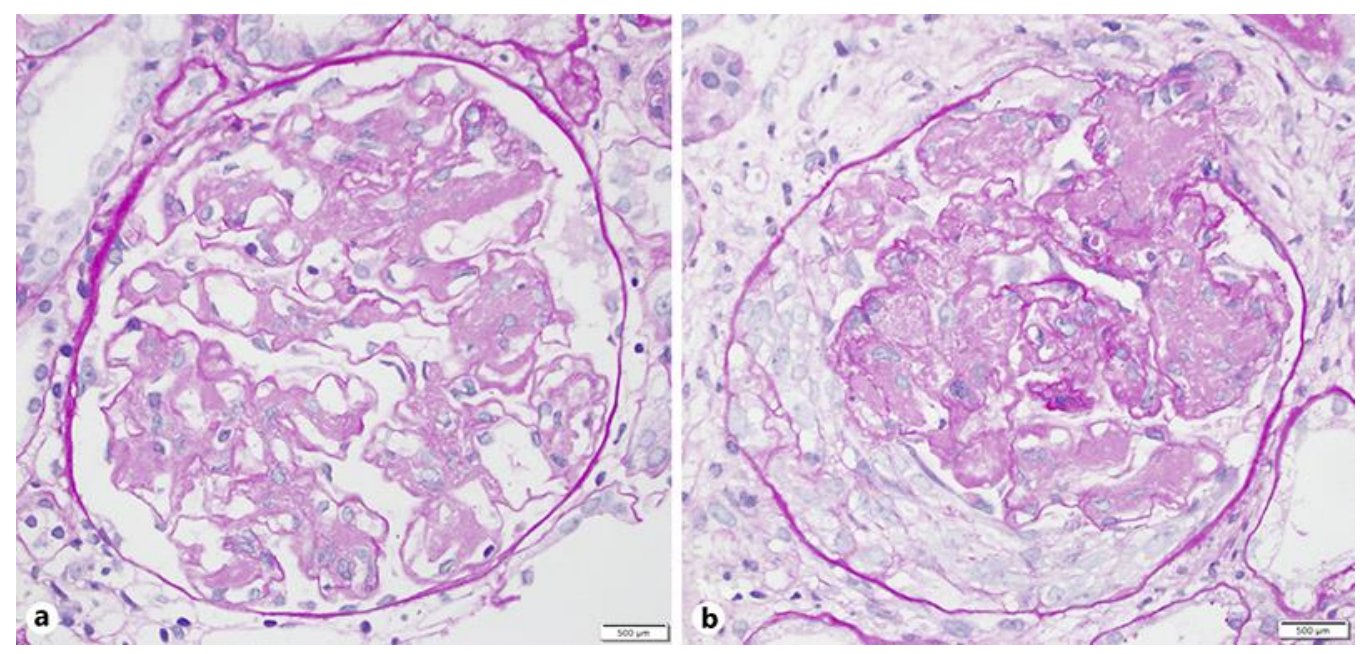

Fig. 1. In the glomeruli, there was diffuse mesangial widening due to deposition of an amorphous substance, which stained weakly with periodic acid-Schiff stain (a). One glomerulus contained a cellular crescent (b). PAS stain, original magnification $\times 40$. 


\section{Case Reports in Nephrology and Dialysis}
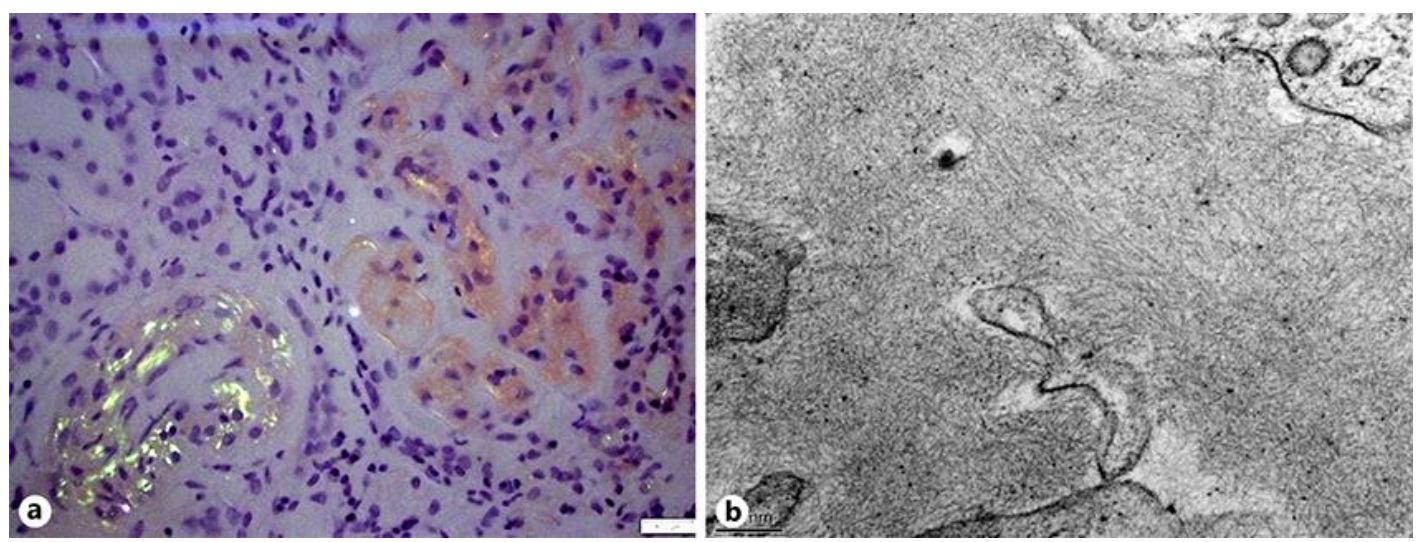

Fig. 2. The deposits in the blood vessel walls and glomeruli exhibited diffuse congophilia. However, while the stained deposits in the blood vessel walls showed strong apple-green birefringence under polarised light, this phenomenon was only seen weakly and focally in the glomerular deposits (a). On electron microscopy, the glomerular deposits were composed of randomly arranged fibrils with a mean diameter of 8 $\mathrm{nm}$ (b). Original magnification $\times 135,000$.

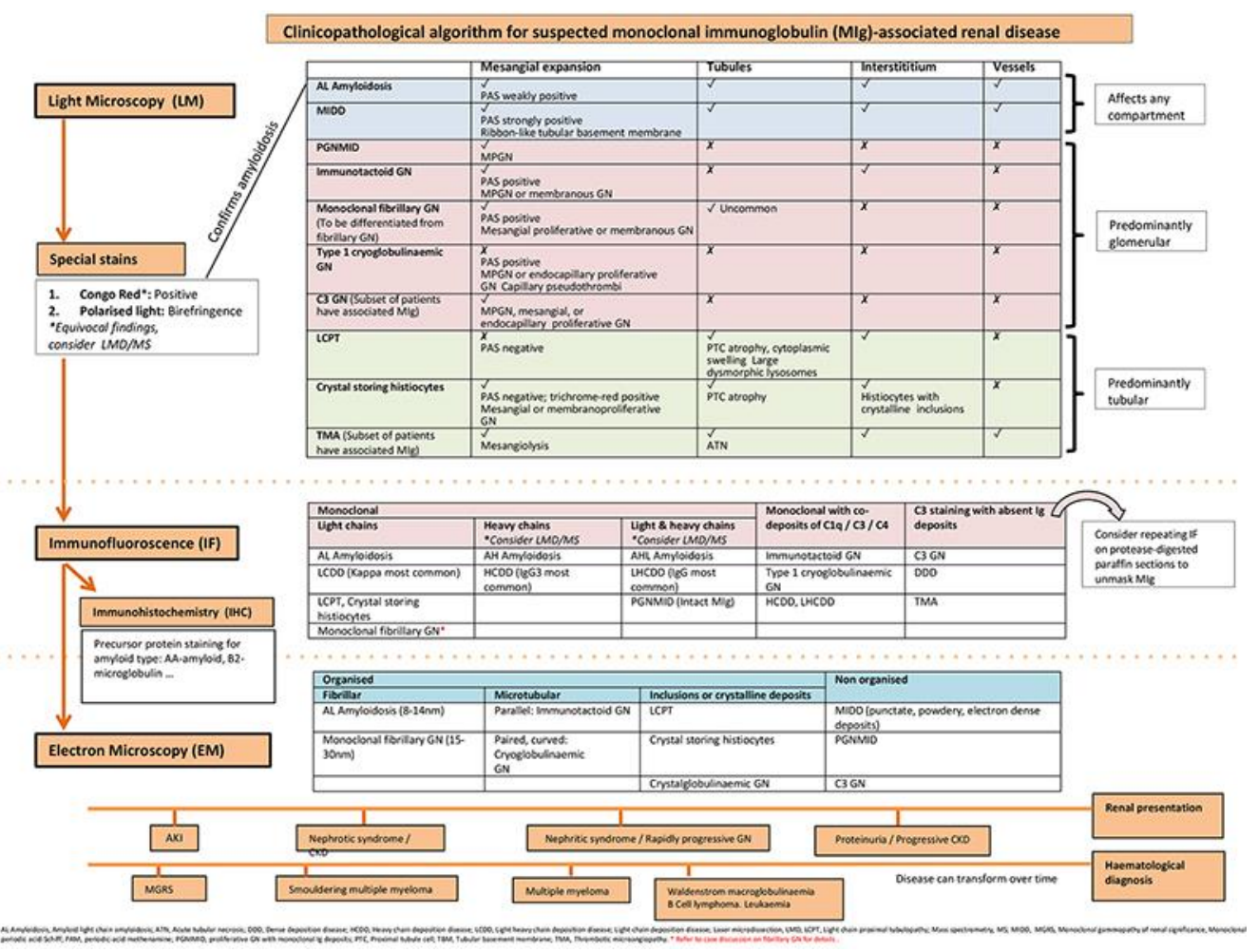

Fig. 3. Proposed clinicopathological algorithm for suspected monoclonal immunoglobulin (MIg)-associated renal disease. 


\section{Case Reports in Nephrology and Dialysis}

Table 1. Results of the initial laboratory investigations

\begin{tabular}{|c|c|c|}
\hline & Result & Normal range \\
\hline \multicolumn{3}{|l|}{ Blood } \\
\hline Haemoglobin & $10.1 \mathrm{~g} / \mathrm{dL}$ & $11.4-14.7 \mathrm{~g} / \mathrm{dL}$ \\
\hline Platelets & $312 \times 10^{9} / \mathrm{L}$ & $164-387 \times 10^{9} / \mathrm{L}$ \\
\hline Sodium & $141 \mathrm{mmol} / \mathrm{L}$ & $135-145 \mathrm{mmol} / \mathrm{L}$ \\
\hline Potassium & $3.6 \mathrm{mmol} / \mathrm{L}$ & $3.5-5.0 \mathrm{mmol} / \mathrm{L}$ \\
\hline Urea & $7.3 \mathrm{mmol} / \mathrm{L}$ & $2.0-4.5 \mathrm{mmol} / \mathrm{L}$ \\
\hline Creatinine & $270 \mu \mathrm{mol} / \mathrm{L}$ & $60-107 \mu \mathrm{mol} / \mathrm{L}$ \\
\hline Albumin & $27 \mathrm{~g} / \mathrm{L}$ & $38-48 \mathrm{~g} / \mathrm{L}$ \\
\hline Adjusted calcium & $2.36 \mathrm{mmol} / \mathrm{L}$ & $2.15-2.55 \mathrm{mmol} / \mathrm{L}$ \\
\hline Lactate dehydrogenase & $548 \mathrm{U} / \mathrm{L}$ & $250-580 \mathrm{U} / \mathrm{L}$ \\
\hline Infection serology & Negative for HBV, HCV and HIV & \\
\hline C-reactive protein & $<5 \mathrm{mg} / \mathrm{dL}$ & $10-45 \mathrm{mg} / \mathrm{dL}$ \\
\hline Complement & Normal & - \\
\hline Anti-nuclear antibody & Negative & - \\
\hline Anti-GBM & Negative & - \\
\hline ANCA & Negative & - \\
\hline Serum M-protein & Negative & - \\
\hline \multirow[t]{2}{*}{ FLC assay } & Kappa FLC: 38.8 mg/L & Kappa: 3.3-19.4 mg/L \\
\hline & Lambda FLC: 1,176.0 mg/L & Lambda: $5.7-26.3 \mathrm{mg} / \mathrm{L}$ \\
\hline Immunofixation & Lambda light chain restriction & \\
\hline Serum amyloid A protein & $4 \mathrm{mg} / \mathrm{L}$ & $0-322 \mathrm{mg} / \mathrm{L}$ \\
\hline \multicolumn{3}{|l|}{ Urine } \\
\hline Leukocytes & 1/HPF & - \\
\hline Erythrocytes & $1 / \mathrm{HPF}$ & - \\
\hline Estimated total urine protein & $19.0 \mathrm{~g} / \mathrm{L}$ & $<0.2 \mathrm{~g} / \mathrm{L}$ \\
\hline Casts & Not seen & - \\
\hline
\end{tabular}

HBV, hepatitis B virus; HCV, hepatitis C virus; HIV, human immunodeficiency virus; Anti- GBM, antiglomerular basement membrane; ANCA, anti-neutrophil cytoplasmic antibody; FLC, free light chain; HPF, high-power field. 


\section{Case Reports in Nephrology and Dialysis}

\begin{tabular}{l|l}
\hline Case Rep Nephrol Dial 2020;10:95-103 \\
\hline DOI: 10.1159/000508785 & $\begin{array}{l}\text { (c) } 2020 \text { The Author(s). Published by S. Karger AG, Basel } \\
\text { www.karger.com/cnd }\end{array}$ \\
\hline
\end{tabular}

Chang et al.: Multiple Myeloma-Associated Light Chain Amyloidosis and a Proposed Approach to Monoclonal Immunoglobulin-Associated Renal Disease

Table 2. Proposed indications for use of LMD/MS proteomics for amyloid typing in native kidney biopsies

1 Equivocal Congo red staining, where fibrillary glomerulonephritis cannot be ruled out after thorough clinical and haematological evaluation

2 Positive IF staining for immunoglobulin heavy chains, with or without light chain staining, with or without positive IHC staining for serum amyloid A protein

3 Equal IF staining for kappa and lambda light chains, despite repeating IF on pronase-digested paraffin tissue

4 Unusual glomerular features such as endocapillary or extracapillary proliferation in the context of renal amyloid 